Article

\title{
Spotlight on Leadership Path-Goal Theory Silos in Practice to Improve and Sustain Job-Oriented Development: Evidence from Education Sector
}

\author{
Atif Saleem ${ }^{1,+} \oplus^{\circ}$, Ling $W u^{1, *,+} \oplus$, Sarfraz Aslam ${ }^{2,3} \mathbb{1}$ and Tianxue Zhang ${ }^{1, *}$ \\ 1 College of Teacher Education, College of Education and Human Development, Zhejiang Normal University, \\ Jinhua 321004, China; ad668@nenu.edu.cn \\ 2 School of Education, Shaanxi Normal University, Xi'an 710062, China; sarfrazmian@nenu.edu.cn \\ 3 Foreign Language Department, Yulin University, Yulin City 719000, China \\ * Correspondence: wulingzj2020@zjnu.edu.cn (L.W.); tianxuezh@126.com (T.Z.) \\ + A.S. and L.W. have contributed equally to this work and shared first authorship.
}

Citation: Saleem, A.; Wu, L.; Aslam, S.; Zhang, T. Spotlight on Leadership Path-Goal Theory Silos in Practice to Improve and Sustain Job-Oriented Development: Evidence from Education Sector. Sustainability 2021, 13, 12324. https://doi.org/10.3390/ su132112324

Academic Editor: Virginia Bodolica

Received: 16 September 2021

Accepted: 21 October 2021

Published: 8 November 2021

Publisher's Note: MDPI stays neutral with regard to jurisdictional claims in published maps and institutional affiliations.

Copyright: (c) 2021 by the authors. Licensee MDPI, Basel, Switzerland. This article is an open access article distributed under the terms and conditions of the Creative Commons Attribution (CC BY) license (https:// creativecommons.org/licenses/by/ $4.0 /)$.

\begin{abstract}
Sustainable development is a process occurring on several levels, which placed the expectations on educational institutions, especially secondary schools, change radically. Schools, therefore, are gradually likely to emphasize enhanced and sustainable teaching practices under the agenda of the United Nations 2030, sustainable future. Hence, the job-oriented development of teachers is a critical factor of the school leadership mechanism. Considering this, the present empirical research was designed to study the mechanism of path-goal theory (PGT) to sustain teachers' job-oriented development in private secondary schools in Pakistan. The viewpoint of teachers, whose job performance is ultimately affected by the school leadership behavior and who perform the job at the front line in schools, was taken on board for the investigation. A total of 2469 secondary school teachers from 785 private secondary schools participated in the present study. Confirmatory factor analysis, t-test, Pearson correlation, and path analysis structural equation modeling analytics were mainly involved in the data analysis. Overall, the findings substantiated the constructive PGT mechanism, especially indicating that directive leadership is the most influential and effective leadership behavior in complex tasks, including when teachers are inexperienced. Moreover, the helpful role of supportive leadership and achievement-oriented leadership behaviors backs up the directive behavior. Although participative leadership behavior was problematic in the studied schools, it should be constructively adopted, as it was found to be a statistically significant predictor. Therefore, training programs for school leaders with good experience in participatory leadership functions can be productive for long-term teachers' motivation. The literature shows that several secondary school teachers still perform poorly because of inadequate leadership, and the viewpoint of teachers on PGT was ignored in earlier studies. Hence, there was a dire need to conduct this research to address these concerns, especially in the non-Western, Asian context. In addition to pioneering academic research on leadership PGT in the secondary school context, the PGT elements were investigated, including teachers' extrinsic and intrinsic motivation for the first time, adding new understanding about the theory.
\end{abstract}

Keywords: sustainable development; leadership; UNO agenda 2030; path-goal theory; school leadership; teacher job performance; educational institutions

\section{Introduction}

In the present 21st century, under the leadership of united nation organization (UNO), education as a sustainable development agenda 2030 (SD) has been characterized by multifaceted progress in terms of education toward sustainable societies and a sustainable future $[1,2]$. Therefore, the leadership process in educational institutions including schools is a critical factor to sustain the job-oriented development of teachers, which leads towards 
improved teaching practices in schools. As proof of concept, the UNO's sustainable development target 4.7 draws our attention towards workforce skill and knowledge, specifically job development [3,4].

The expectations placed on educational institutions, especially secondary schools, are changing radically. In addition to cost effectiveness, schools are gradually likely to put emphasis on societal objectives. Sustainable development is a process occurring on several levels, i.e., secondary schools. A school is a teaching and learning institution where a society's youth are refined through formal education. The effective arrangement of educational and management activities within the school system depends primarily on the human factor because leadership has been an attractive phenomenon for the last few decades $[5,6]$, which is liable to improve the performance of the workforce. There are two categories of human aspects: the teaching staff and non-teaching staff.

Secondary school heads are the senior staff who, because of their qualifications, intellect, or expertise and teaching experience, are assigned to pilot the affairs of schools. Head officers or managers take the apex role in the organizational structure in private schools. They may also be viewed as the leading officials who make major decisions to achieve the school's objectives (Bass, 1999) by promoting teacher job performance. This research was carried out to study how principal leadership promotes teacher job performance in secondary schools.

In practice, education leaders are problem solvers and facilitators $[7,8]$; they must offer good education by delivering excellent facilities for teaching. Therefore, principal leadership is a significant component of success in a school where teaching and learning formally occur to educate society's youth.

Nsubuga [9] argued that many teachers at secondary schools perform poorly because of inadequate principal leadership. Imhangbe, et al. [10] reported that the principal behaviors of school leaders affect the teachers' work performance either positively or negatively, directly or indirectly. Therefore, principal leadership is essential to promote teachers' job-oriented development in schools. With that in mind, there was a dire need to conduct research that addressed these concerns, especially in the context of private secondary schools in Pakistan.

\subsection{The Context: Share of Private Secondary Schools in Education of Pakistan}

In Pakistan in general, the significance, position, and desirability of leading leadership participation for school performance are non-negotiable and regularly referenced with regard to the development of the country because the country's education industry produces responsible citizens and human power to achieve the National Education Goals MOFEPT, [11] for the attainment of the state's educational objectives [12,13].

In Pakistan, private schools are the main contributors to the completion of Millennium Development Goals (MDGs). The private sector has a 37\% share of the country's educational institutes; out of this $37 \%$ of institutions, $47.5 \%$ of students as well as $48 \%$ of teachers are in the private education sector, while, at the secondary education level (IX-X), private schools account for about 60\% MOFEPT, [11]. Hence, the country has more private secondary schools than public sector secondary schools. This substantial growth is a challenge for school administrators, policy makers, and principals in terms of providing excellent teaching services for quality education in the country. Therefore, this study was conducted in private secondary schools in Pakistan.

The National Education Policy 2017-2025 of Pakistan declares that the state can provide compulsory education up to matriculation for all children aged 5 to 16 MOFEPT, [11]. This national agenda of education provision has become children's fundamental right, satisfying the United Nation's (UN) Sustainable Development Goals (SDGs) that cover MDGs and "Education For All" MOFEPT, [11].

Of the national goals, educational institutions including schools, colleges, and universities, in both the public and private sectors, play crucial roles in achieving the targets. Therefore, private secondary school principals must carry out several administrative func- 
tions, i.e., supervising teaching and learning activities, pedagogy, and the curriculum process [14]. The main purpose of this role is to assist and direct teachers in translating instructions from head offices and the content of the curriculum or syllabus into workable learning lessons [15] to justify the Standard Operating Procedures (SOPs). Hence, this investigation was conducted to study the role of principal leadership to promote teachers' job performance in private secondary schools in Pakistan.

\subsection{Path-Goal Theory}

Path-goal theory (PGT) (Figure 1) serves, for principals, as an instrument to eliminate the obstructions and problems that prevent teachers from improving their job performance. The path-goal theory of leadership was first reported in the 1970s in the works of Evans [16], House [17], House and Dessler [18], and House and Mitchell [19] as drawing heavily from the literature on leadership. It was updated in the work of House $[20,21]$.

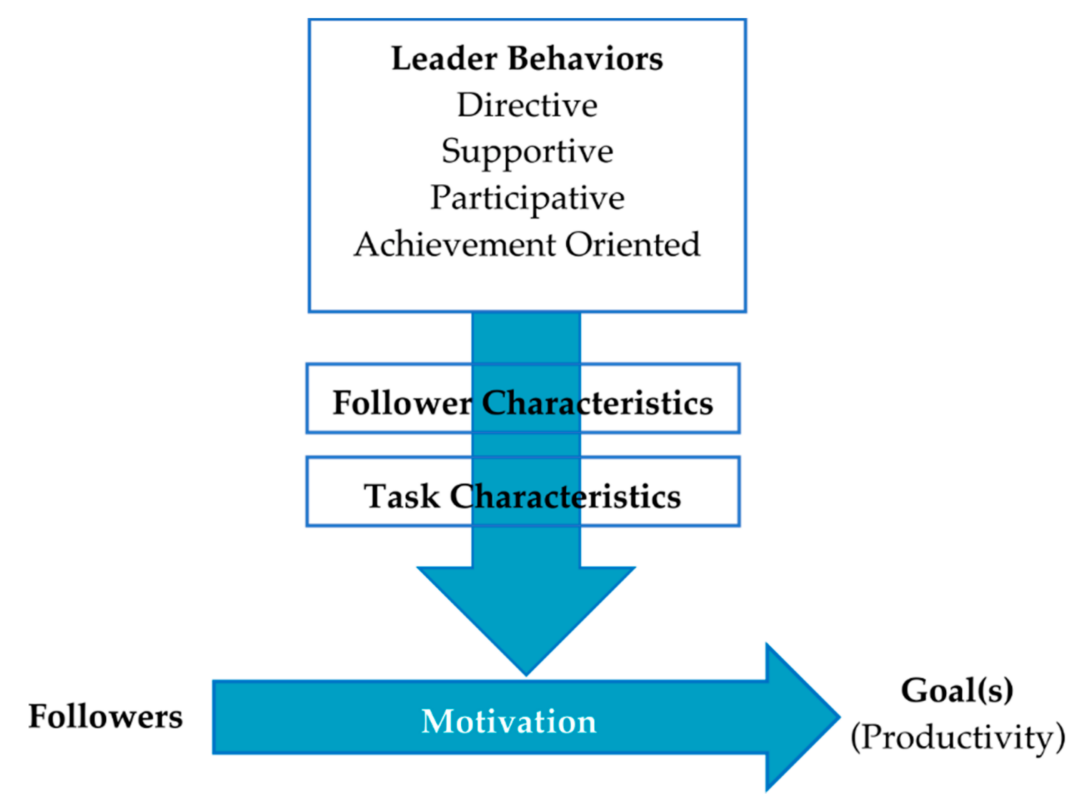

Figure 1. Adopted from Northouse [21].

According to Northouse [21], directive leaders typically offer task directions and do not include teachers in policy making or significant administrative decision making in schools; participatory leadership empowers followers and integrates their opinions and ideas into the policy process; and supporting leadership actively provides support to followers to enhance the process of leadership guidance for teachers' job-oriented development. Furthermore, supportive leadership provides favorable working conditions to encourage strong morality, trustworthiness, a sense of dignity, etc., in order to achieve ambitious goals. Therefore, achievement-oriented leadership focuses on helping leaders set attractive targets and goals. As a result, teachers are inspired and participate actively and energetically in the teaching and learning process.

Task characteristics can be defined as followers' task design, organization formal authority system, and primary workgroup. Teachers' training has paid particular attention to followers' affiliation needs, preference structure, self-perceived level of task ability, and locus of control. These characteristics collectively motivate teachers to accomplish their goals and perform their jobs effectively and efficiently [21,22].

These characteristics could be a source of job-oriented development of teachers; teachers realize that they can accomplish desired goals and that their work is useful, which raises teachers' confidence to the highest level. The characteristics of the tasks and the teachers determine the interpretation of leader behaviors to enhance teachers' motivation to achieve the school's goals in a given organizational work setting. 
Principals, as heads of education institutions, must augment teacher job performance. Research indicates that motivation plays a pivotal role in promoting and sustaining teacher job performance, which can be enhanced when there is an established system of motivation. Generally, there are two forms of motivation: extrinsic and intrinsic [23]. Extrinsic motivation alludes to performing the job enthusiastically due to the receipt of rewards, while intrinsic motivation refers to job pleasure without the attraction of a prize [24]. However, PGT and prior research considered teachers' motivation as a single variable, meaning they combined extrinsic and intrinsic motivation into one factor and ignored the separate roles of extrinsic and intrinsic motivation in affecting the job-oriented development of teachers in the long run because extrinsic and intrinsic motivation denote institutional directions and job intensity $[23,24]$. Thus, this research also explored the role of extrinsic and intrinsic motivation.

\subsection{Complexity of the Theory}

The path-goal theory is paradoxically confusing due to its broad range and interrelating assumptions set about the leadership process; it covers multiple heterogeneous leadership aspects [21]. The theory differentiates between four behaviors that interact with the characteristics of teachers and tasks, as well as teachers' motivation to clarify challenging objectives to finish assignments effectively by following SOPs in the school context.

In the school context, therefore, the selection of one leadership behavior combining all these characteristics is a challenging activity. Pragmatically, the theory needs those school leaders and administrators who guide, assist teachers, and eliminate obstructions preventing teachers from completing their jobs and attaining their goals. In addition, PGT integrates expectation theory concepts, which empower the followers (teachers) to make a reasonable contribution through their efforts and work [25]. However, PGT does not sufficiently clarify the relationship between principal leadership behaviors and teachers' job performance. For example, it does not sufficiently illustrate the positive role of leadership behaviors in promoting, particularly, teachers' job-oriented development by notifying teacher characteristics, task characteristics, and teacher motivation in one school day.

Therefore, the principals do not clearly understand how their leadership informs the teacher job performance sub-categories. Notably, it does not distinguish between teacher motivation as extrinsic and intrinsic. Consequently, it offers an inadequate description of the mechanism of the constructs of PGT: (1) directive, (2) participative, (3) supportive, and (4) achievement-oriented leadership behaviors; contingency factors: (1) task characteristics, (2) teacher characteristics, and (3) teacher motivation [21]; and various job sub-categories to sustain teachers' job performance in terms of the following teacher job performance standards: (1) teacher leadership, (2) classroom atmosphere and discipline, (3) monitoring and evaluation, (4) classroom organization, and (5) teaching planning [26]. Thus, this study was conducted to explicate these concerns and the mechanism of PGT.

\subsection{Teacher Job Performance Standards}

The basic ambition of schools is teaching and learning. They provide a societal basis for developing young people. School leaders guide and direct teachers in fulfilling this ultimate goal. The progress of teacher efforts depends on how the leadership promotes teaching and learning in schools $[27,28]$.

To strengthen the process of teaching, it is essential to classify multidimensional key performance indicators (KPIs) in the job performance standards of teachers according to the planned objective frameworks, teachers' performance factors, and skill standards [29] in terms of teacher leadership, classroom atmosphere and discipline, monitoring and evaluation, classroom organization, and teaching planning $[26,30]$.

The drafting of lesson plans, class events, and collections of teaching and/or classroom activities are labeled teaching planning [31]. The arrangement of classrooms includes organizing classroom furniture, arranging student seating, studying the core materials, understanding the physical conditions of the classroom, and learning participation [32-34]. 
Student methods of learning assessment include homework checking, tests, exams, and all relevant evaluation techniques, recognized as monitoring and evaluation [35-37]. A secure, stable, pleasant, and reasonable classroom atmosphere and discipline are maintained for effective learning and adequate and convenient communication [36,38]. Student positive influence, mentoring, guidance, and motivation comprise teacher leadership, which is the fifth sub-category of the teachers' job [14].

\subsection{Principal Leadership and Teacher Job Performance}

Pragmatically, school principals are problem solvers and facilitators [7,8]. In particular, leaders play an important role in promoting the performance of teachers in private secondary schools. Hamilton [6] indicated that school leaders have a significant influence on school success. School leaders and managers influence the success of teachers by directly or indirectly utilizing their leadership behavior. The main roles and functions of school administration are to sustain curriculum standards, assess teaching methods, monitor student achievement, facilitate teachers, and make arrangements to create a positive and high-achievement environment in which to reach challenging goals. Eliminating obstacles and clarifying how teachers perform their work are important aspects of PGT efficiencies and effective leadership (Northouse, 2018).

Many studies on PGT have been conducted to determine the direct impact of school principals' four behaviors on teacher job performance. For instance, Saleem, Aslam, Yin, and Rao [26] found that directive leadership is the most effective leadership style in private secondary schools in Pakistan. However, this study was partial because it did not consider the contingency factor, thereby creating a gap for the present investigation to fill.

Moreover, Atsebeha [30] observed the impact of leadership styles on the job performance of teachers in primary schools in Tigray, Ethiopia. Similarly, Imhangbe, Okecha, and Obozuwa [10] investigated the impact of principal leadership behaviors on the performance of teachers in public senior secondary schools in Edo, Nigeria. They found that effective teacher job performance was the result of democratic leadership; however, they ignored sub-categories of teachers' jobs.

Other investigations of this striking phenomenon were also carried out [39-42]. However, these investigations were only partial because contingency factors were ignored, and they holistically recorded teacher job performance. In short, previous studies evaluated teacher performance as one variable or component and did not go deep into the aforementioned sub-categories. Specifically, PGT contingency factors, i.e., teacher characteristics, task characteristics, and teacher extrinsic and intrinsic motivation, were appallingly ignored. Hence, there was a gap in knowledge.

Although previous studies are enlightening, all the investigations measured the KPIs of teacher job performance as one performance factor and neglected PGT contingency factors and teacher job performance sub-categories. Therefore, school leaders, including principals, fail to understand the aspects of their leadership to promote the job-oriented development of teachers. As a result, teachers' efficiency and productivity decrease because of low performance. Low output and productivity also lead to high turnover rates, demotivation, and work discontent $[43,44]$. In the end, school objectives would not be met and overall performance - in particular, returns-would decline. This research was conducted to address these concerns.

In addition, the PGT mechanism and relationships and effects of each component of the theory on the KPIs of teachers' jobs must be clarified, as such relationships and consequences would provide a full understanding of the mechanism of PGT, which will help school leaders, supervisors, coordinators, and principals address the problems of different leadership behaviors. Consequently, the efficiency and level of teachers' jobs will be elevated. In this way, this study addresses the dearth of knowledge. Likewise, previous studies have not adopted advanced analytical models, for example, confirmatory factor analysis as well as the path analysis analytic of structural equation modeling (SEM) [45]. In addition, this investigation is a pioneer study because it tests the path-goal theory con- 
taining all its factors and going deep into the extrinsic and intrinsic motivation to explicate its mechanisms. Thus, this study contributes to the leadership literature, particularly the PGT literature.

\subsection{Purpose of the Study}

To fill the aforementioned research gaps, the current empirical study was designed to assess how the mechanism of PGT promotes teachers' job-oriented development in private secondary schools in Pakistan.

\section{Methodological Procedures}

\subsection{Participants and Procedures}

The present research included a sample of teachers from 785 private secondary schools in the province of Punjab, Pakistan. To choose the sample schools, two principles were followed. First, considering the province of Punjab as a large area in terms of population, the sampled schools had to cover various regions of the province, excluding federal territory. The province has nine boards of intermediate and secondary education (BISE), which are responsible for conducting secondary and higher secondary exams. Thus, a sample of the current study was selected from all these boards' jurisdictions. As a result, there were 84 to 90 private secondary schools in each BISE: BISE Lahore, 89 schools; Gujranwala, 87 schools; Bahawalpur, 85 schools; Rawalpindi, 90 schools; Faisalabad, 88 schools; DG Khan, 86 schools; Multan, 84 schools; Sargodha, 87 schools; and BISE Sahiwal, 89 schools.

Second, in terms of school administration, there were two kinds of private schools in the province: (1) centralized school chains with administrative head offices and (2) autonomous schools without any school branch. Both private school systems teach the same syllabus approved by the government authorities, named the Punjab Text Board (PTB). Of the sample, therefore, no major differences existed in terms of school characteristics.

During the research, paper questionnaires were used. From September 2020 to March 2021, data collection was carried out. Each sampled school was given four to nine copies of the questionnaire based on how many secondary section school teachers worked there.

The random sampling technique was used to select the participating teachers from each surveyed school. Only secondary teachers were encouraged to respond to the questionnaire. Though participants were invited to take part in the main courses they had been teaching, the survey did not collect details about their year of schooling, which composed a restriction in this research.

A total of 4122 copies of the questionnaire were distributed in a total of 785 private secondary schools, and $2469(59.90 \%)$ valid copies were returned. It is noteworthy that a similar percentage of 1268 teachers $(51.36 \%)$ were from centralized school chains; the other 1201 teachers (48.64\%) were from autonomous schools. In terms of gender distribution, there were 1260 men (51.03\%) and 1209 women (48.97\%).

\subsection{Instruments}

\subsubsection{Path-Goal Theory Questionnaire (PGTQ)}

In total, 20 items for the PGTQ validated by Indvik [46] were used to assess the leadership behaviors: directive, participative, supportive, and achievement-oriented leadership. Five items on each behavior collectively composed a leadership behavior. The last single item was asked to assess the leadership behavior that the principals often used on a school day.

In addition, the 30 items of the self-constructed part of the PGTQ for PGT contingency factors were used; the self-constructed part was developed in the light of the studies of $[17,21,22,30]$. It contained seven items for task characteristics, nine items for teacher characteristics, and seven items for intrinsic motivation and extrinsic motivation, respectively. 


\subsubsection{Teacher Job Performance Questionnaire (TJPQ)}

In total, 34 items for the TJPQ validated by Saleem, Aslam, Yin, and Rao [26] and Atsebeha [30] were used to assess teacher job performance. Seven teaching preparation elements were included in the TJPQ questionnaire for teaching planning KPI; six were for structure in the classroom as classroom organization KPI and seven were for tracking and assessment as monitoring and evaluation KPI, and class environment and instruction as classroom atmosphere and discipline KPI. The least was teacher leadership KPI.

\subsection{Instrument Adaption Procedures}

All statements of PGLQ objects were slightly modified as an instrument adaptation from "I" to "our principal" and "followers" to "teachers", i.e., "I let followers know what is expected of them" to "Our principal lets the teachers know what is expected of them". Items 5, 6, 9, and 13 of the TJPQ had some modifications, for instance, "establishes the guidelines and maintains order and discipline in the classroom" to "teachers talk from time to time about positive language usage, ethics, and norms for continued classroom discipline". The rest remained the same.

The school administrators ensured modifications, improvements, and overall look, including face and construct validity of the instruments. The administrators had legitimate authority, prepared rules, and SOPs to conduct teachers' activities, and carried out performance evaluations. To assess teachers' perspectives on the research subject, a five-point Likert scale $(1=$ strongly disagree to $5=$ strongly agree $)$ was used for all the measures of both questionnaires.

\subsection{Data Analysis Protocol}

To verify the missing response patterns, the missing value analysis with SPSS 26 was first performed. A test of normality and outlier deduction was conducted and found to be satisfactory after problematic cases were excluded. More to the point, no variable with $5 \%$ or more missing values was found, and the number of missing values ranged from 0 to $1.3 \%$ for all the items. The missing data were found to be randomly missing and the expectation-maximization algorithm was used to resolve this issue (Little's MCAR test: $\left.\chi^{2}=9572.68, \mathrm{df}=7194, p<0.01\right)$.

In the current study, the Pearson correlation, t-test, CFA (confirmatory factor analysis), and SEM (structural equation modeling) path analysis techniques were primarily included in the data analysis. The analysis was performed in SPSS and Amos version 26.

More precisely, CFA was employed to determine the reliability and validity of the measures. An alpha coefficient of Cronbach was used to verify the internal consistency of each subscale. Descriptive statistics were determined, and a t-test was used to identify the gender influence differences on the constructs. Because of the strength of analyzing complex relationships between several latent variables simultaneously and tracking for measurement error, SEM path analysis using AMOS was employed to study the mechanism of PGT to sustain the job-oriented development of teachers.

In the use of SEM and CFA, several indices were employed to show the robustnessof-fit in confirmatory factor analysis and path-analysis SEM analytics. In addition to the chi-square statistic, the RMSEA (root mean square error of approximation), NNFI (nonnormed fit index), and CFI (comparative fit index) goodness-of-fit metrics were used in the research. The SEM literature indicates that the fit of data is appropriate when both CFI and NNFI are no less than 0.90; for RMSEA, an ideal fit requires it to be under 0.08 (see appendix for model-fit thresholds).

\subsection{Ethical Considerations}

Concerning research ethics, after receiving permission from head offices, administrators and teachers participated voluntarily in the study. They were allowed to pull back their consent at any time prior to the analysis. Participant personal information and other associated information were encrypted immediately after the analysis. 


\section{Findings}

\subsection{Construct Reliability and Validity}

The original PGTQ questionnaire had five elements for each of the four leadership behaviors, seven items for task characteristics, nine items for teacher characteristics, and seven items for intrinsic and extrinsic motivation.

In the TJPQ questionnaire, teaching planning, monitoring and evaluation, classroom atmosphere and discipline, and teacher leadership had seven items, while classroom organization had six items. In confirmatory factor analysis, items with a chi-square/df over 0.5 were omitted [47]. The other items were conserved.

All PGTQ items of leadership behavior remained unchanged but the self-constructed PGT contingency factor part dropped to six for task characteristics, seven for teacher characteristics, five for intrinsic motivation, and six for extrinsic motivation for the flow of constructs. Meanwhile, TJPQ's teaching planning and teacher leadership dimensions had five items, and class organization, classroom atmosphere and discipline, monitoring and evaluation dimensions had four items for the consistent delivery of constructs.

The reliability of the questionnaire was first evaluated in terms of consistency and composite reliability. The internal uniformity of each construct was evaluated with Cronbach's $\alpha$. Table 1 shows $\alpha$ values for PGTQ in the range of 0.78 to 0.87 and for TJPQ between 0.82 and 0.88 . All alpha values were found to be above the 0.6 threshold, which is an acceptable level of reliability [48]. Therefore, the constructs were considered to be reliable [49]. In addition, the table demonstrates CR "composite reliability" values ranging from 0.80 to 0.91 for PGTQ and 0.78 to 0.90 for TJPQ, thus exceeding the 0.7 threshold [47].

Table 1. Internal consistency and composite reliability.

\begin{tabular}{lccc}
\hline Constructs & $\alpha$ & CR & AVE \\
\hline Directive Leadership & 0.86 & 0.87 & 0.79 \\
Participative Leadership & 0.80 & 0.91 & 0.82 \\
Supportive Leadership & 0.87 & 0.82 & 0.76 \\
Achievement-oriented Leadership & 0.84 & 0.80 & 0.76 \\
Task Characteristics & 0.80 & 0.88 & 0.75 \\
Teacher Characteristics & 0.81 & 0.90 & 0.78 \\
Extrinsic Motivation & 0.82 & 0.91 & 0.79 \\
Intrinsic Motivation & 0.78 & 0.89 & 0.73 \\
Teaching Planning & 0.88 & 0.83 & 0.77 \\
Classroom Organization & 0.83 & 0.89 & 0.74 \\
Monitoring and Evaluation & 0.85 & 0.78 & 0.79 \\
Classroom Atmosphere and Discipline & 0.82 & 0.85 & 0.81 \\
Teacher Leadership & 0.87 & 0.90 & \\
\hline
\end{tabular}

$\alpha$, Cronbach alpha values; $\mathrm{CR}$, composite reliability; $\mathrm{AVE}$, average variance extracted.

Second, the validity of the construct can be accomplished by the use of convergent validity and discriminant power. The extent of discriminatory power can be obtained through independent $t$-testing. Figure 2 shows the $t$-test values for PGTQ ranging from 51.43 to 86.21 and demonstrates TJPQ values of 50.88 to 82.95 ; all $t$-values demonstrated in Figure 2 were found to be significant on the scale of $p<0.01$. Each $t$-value over the threshold of the 3 critical ratio was found to be discriminant [50]. 


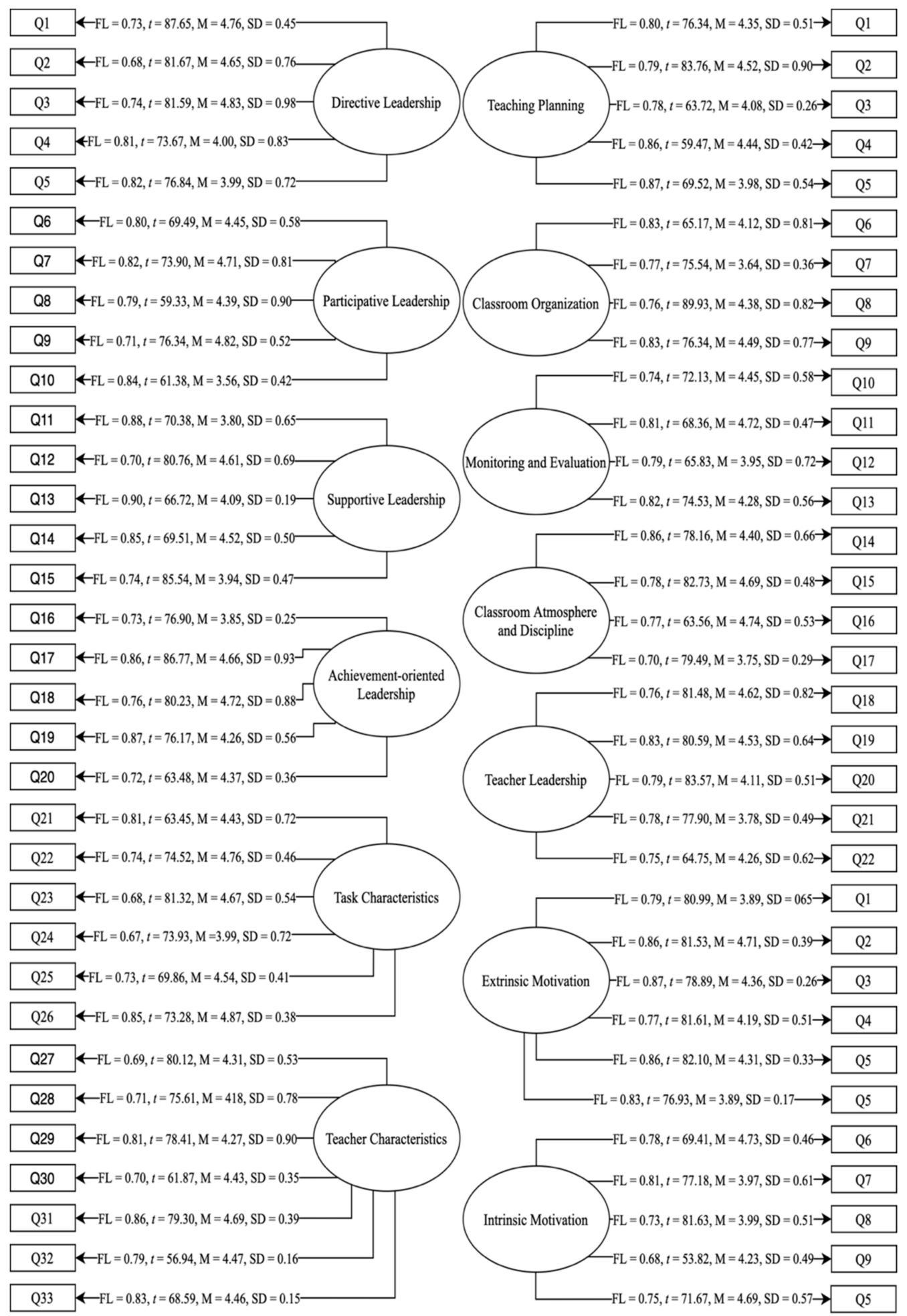

Figure 2. Reliability and validity measures; FL, factor loadings; t, t-values; M, mean score; SD, standard deviation.

In addition, factor loading (FL) and average variance extracted (AVE) composed convergent validity. All FL values ranging from 0.70 to 0.87 for PGTQ and from 0.67 to 0.90 for TJPQ and AVE values in the range of 0.73 to 0.82 for PGTQ and 0.74 to 0.81 for TJPQ were found to be satisfactory on the gauge of 0.6 [47], confirming convergent validity (see Table 1). Hence, the construct reliability and validity of instruments were reached on the satisfactory level. 


\subsection{Pattern of Leadership Behaviors}

Among the four PGT leadership behaviors, teachers pointed out that 384 school principals often used directive leadership behavior. Moreover, participative, supportive, and achievement-oriented leadership behaviors were often employed by 95, 142, and 164 principals, respectively (Figure 3).

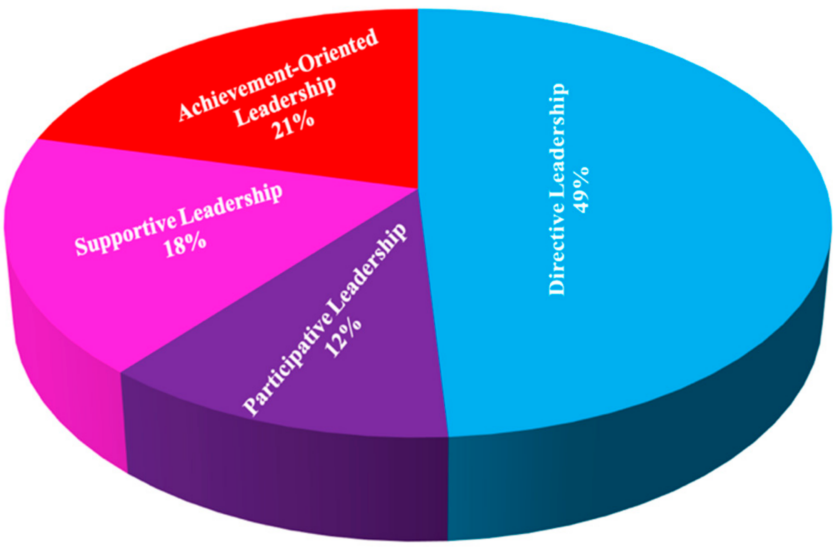

Figure 3. Pattern of leadership.

\subsection{Gender Differences}

Table 2 shows a small effect size of gender differences only for directive leadership $(d=0.10)$, task characteristics $(d=0.09)$, and monitoring and evaluation $(d=0.12)$. Thus, the combination of male and female viewpoints into particular variables was judged to be appropriate [51].

Table 2. Gender differences among the constructs.

\begin{tabular}{|c|c|c|c|c|c|c|c|}
\hline \multirow[b]{2}{*}{ Constructs } & \multicolumn{2}{|c|}{$\begin{array}{l}\text { Male }=51 \% \\
N=1260\end{array}$} & \multicolumn{2}{|c|}{$\begin{array}{l}\text { Female }=49 \% \\
N=1209\end{array}$} & \multirow[b]{2}{*}{$\mathbf{F}$} & \multirow[b]{2}{*}{$\mathbf{t}(\mathbf{d f})$} & \multirow[b]{2}{*}{ d } \\
\hline & $\mathbf{M}$ & SD & $\mathbf{M}$ & SD & & & \\
\hline Directive Leadership & 4.43 & 0.21 & 4.16 & 0.27 & 2.18 & $1.82(2085) *$ & 0.10 \\
\hline Participative Leadership & 3.45 & 0.36 & 3.43 & 0.39 & 0.52 & $-0.92(2085)$ & 0.16 \\
\hline Supportive Leadership & 4.54 & 0.28 & 4.35 & 0.31 & 2.03 & $4.12(2085)$ & -0.13 \\
\hline Achievement-oriented Leadership & 4.57 & 0.24 & 4.39 & 0.28 & 2.89 & $1.59(2085)$ & 0.13 \\
\hline Task Characteristics & 4.76 & 0.52 & 4.49 & 0.32 & 2.68 & $1.27(2085) *$ & 0.09 \\
\hline Teacher Characteristics & 4.58 & 0.23 & 4.61 & 0.58 & 0.98 & $3.64(2085)$ & -0.20 \\
\hline Extrinsic Motivation & 4.71 & 0.42 & 4.50 & 0.29 & 0.97 & $-0.57(2085)$ & 0.64 \\
\hline Intrinsic Motivation & 4.39 & 0.27 & 4.56 & 0.53 & 0.72 & $-1.59(2085)$ & 0.47 \\
\hline Teaching Planning & 4.23 & 0.35 & 4.46 & 0.27 & 4.73 & $0.62(2085)$ & 0.16 \\
\hline Classroom Organization & 4.31 & 0.25 & 4.36 & 0.19 & 2.34 & $0.94(2085)$ & -0.34 \\
\hline Monitoring and Evaluation & 4.78 & 0.30 & 4.48 & 0.36 & 1.97 & $1.42(2085) * *$ & 0.11 \\
\hline Classroom Atmosphere and Discipline & 4.52 & 0.26 & 4.19 & 0.23 & 0.79 & $-3.61(2085)$ & 0.23 \\
\hline Teacher Leadership & 4.46 & 0.31 & 4.20 & 0.18 & 2.86 & $1.53(2085)$ & 0.20 \\
\hline
\end{tabular}

${ }^{*} p<0.01,{ }^{* *} p<0.05$.

\subsection{Association and Satisfactory Level of the Constructs}

Table 3 shows revealed, overall, and moderate level associations among PGT leadership behaviors, contingency factors, and teachers' KPIs. However, some insignificant associations were noticed, i.e., achievement-oriented and participative leadership. The correlation coefficients above the threshold of 0.30 were moderately associated, and those above 0.50 were largely associated, at the scale $[52,53]$. In addition, the mean scores of all the constructs including teachers' KPIs were found to be satisfactory except for participative leadership $(\mathrm{M}=3.65, \mathrm{SD}=0.64)$, at the threshold $\mathrm{M} \geq 3.75[14,26]$. In summary, the 
level of teacher job performance and associations among the variables were adequate to proceed with the analysis.

Table 3. Association and satisfactory level of the constructs.

\begin{tabular}{|c|c|c|c|c|c|c|c|c|c|c|c|c|c|}
\hline Constructs & DLS & PLS & SLS & AOLS & TC & TC & EM & IM & TP & $\mathrm{CO}$ & ME & CD & TL \\
\hline DLS & - & & & & & & & & & & & & \\
\hline PLS & $0.28 *$ & - & & & & & & & & & & & \\
\hline SLS & $0.46^{* *}$ & $0.28 *$ & - & & & & & & & & & & \\
\hline AOLS & 0.14 * & 0.34 & $0.59 *$ & - & & & & & & & & & \\
\hline $\mathrm{TC}$ & $0.66^{* *}$ & 0.59 * & 0.56 * & $0.49^{*}$ & - & & & & & & & & \\
\hline TC & 0.53 * & 0.45 * & 0.54 * & $0.57^{*}$ & 0.38 * & - & & & & & & & \\
\hline EM & 0.70 * & $0.66^{*}$ & 0.63 * & $0.73^{* *}$ & $0.63 * *$ & $0.68 *$ & - & & & & & & \\
\hline IM & 0.49 * & $0.47^{*}$ & 0.54 * & 0.64 * & 0.52 * & $0.54^{* *}$ & $0.33 *$ & - & & & & & \\
\hline $\mathrm{TP}$ & $0.75^{*}$ & $-0.20 *$ & 0.51 * & $0.49^{*}$ & 0.67 * & 0.43 * & $0.68^{* *}$ & 0.49 * & - & & & & \\
\hline $\mathrm{CO}$ & 0.58 * & $-0.26 *$ & 0.52 * & $0.62 *$ & 0.45 * & 0.39 * & $0.67 *$ & 0.55 * & -0.33 & - & & & \\
\hline ME & 0.54 * & $0.16^{* *}$ & 0.49 * & 0.54 * & 0.49 * & 0.55 * & 0.59 * & $0.46^{*}$ & 0.33 * & 0.44 & - & & \\
\hline $\mathrm{CD}$ & 0.65 * & $-0.07 *$ & 0.52 * & $0.45 *$ & 0.54 * & 0.36 * & 0.49 * & 0.55 * & $0.17^{* *}$ & $-0.23^{* *}$ & $-0.33 *$ & - & \\
\hline $\mathrm{TL}$ & 0.43 * & $-0.19 * *$ & 0.38 * & $0.55 *$ & 0.46 * & $0.56^{*}$ & 0.51 * & 0.56 * & 0.41 & 0.35 * & $0.08 *$ & 0.12 * & - \\
\hline$M$ & 4.77 & 3.65 & 4.43 & 4.53 & 4.75 & 4.63 & 4.78 & 4.50 & 4.27 & 4.04 & 4.40 & 4.31 & 4.22 \\
\hline$S D$ & 0.53 & 0.64 & 0.50 & 0.39 & 0.46 & 0.29 & 0.42 & 0.35 & 0.31 & 0.29 & 0.58 & 0.54 & 0.28 \\
\hline
\end{tabular}

${ }^{*} p<0.01,2$-tailed, ${ }^{* *} p<0.05$; DLS, directive leadership behavior; PLS, participative leadership behavior; SLS, supportive leadership behavior; AOLS., achievement-oriented leadership behavior; TC, task characteristics; TC, teacher characteristics; EM, extrinsic motivation; $\mathrm{IM}$, intrinsic motivation; $\mathrm{TP}$, teaching planning; $\mathrm{CO}$, classroom organization; $\mathrm{ME}$, monitoring and evaluation; $\mathrm{CD}$, classroom atmosphere and discipline; TL, teacher leadership.

\subsection{SEM-Path Analysis}

SEM-path analysis is a sophisticated graphical analytic used to comprehend complex models, paths, and variances through the use of multiple tests simultaneously, resulting in reliable paths and variances [54]. Hereby, the paths clearly indicated by PGT itself also corroborated the valid use of path analysis in this research (Figures 1 and 3).

The model-fit indices reached the acceptable level $=\chi 2=1987.12 \mathrm{df}=895.09, \chi 2 / \mathrm{df}=2.22$, $p<0.01$, RMSEA $=0.06, \mathrm{GFI}=0.89, \mathrm{AGFI}=0.90, \mathrm{SRMR}=0.06, \mathrm{CFI}=0.92, \mathrm{IFI}=0.94$, $\mathrm{NNFI}=0.93, \mathrm{NFI}=0.95, \mathrm{RFI}=0.91, \mathrm{PNFI}=0.71$, and PGFI $=0.64$ (see Appendix A for model-fit thresholds).

The standard regression coefficient (SRC) weights of the paths are shown in Figure 4. The research model shows that principals' four leadership behaviors significantly predict the contingency factors, which, in turn, significantly predict teachers' motivation. Both types of teacher motivation significantly predict all five KPIs of teacher job performance for sustainable job-oriented development of teachers in the schools.

Overall, the research model shows that directive leadership behavior to task characteristics had the highest SRC $(\beta=0.76, p<0.01)$, followed by supportive leadership to teacher characteristics SRC $(\beta=0.73, p<0.01)$; participative leadership to teacher and task characteristics had the lowest SRC $(\beta=0.31, \beta=0.40, p<0.01)$, correspondingly. Moreover, extrinsic motivation predicted higher SRC weights of KPIs than the intrinsic motivation of teachers, which means that extrinsically motivated teachers' job-oriented development is sustainable in the studied schools.

On the other hand, Table 4 shows the total path predicting the power or impact of principal leadership behaviors on teacher job performance KPIs via contingency factors and teacher motivation types. In total, 80 possible paths were estimated. The path from directive leadership through task characteristics and teachers' extrinsic motivation to teaching planning was found to have the largest SRC $(\beta=0.30, p<0.01)$ weight. This means that directive principals effectively remove the obstacles preventing teachers from performing tasks smoothly and guide their teachers by providing a set of directions when tasks are complex; also, extrinsic teachers' motivation increases teaching planning effectiveness and efficiency. More to the point, directive principals' set of directions in challenging tasks and situations promotes teacher job performance to sustain the job-oriented development of teachers in the studied schools. 


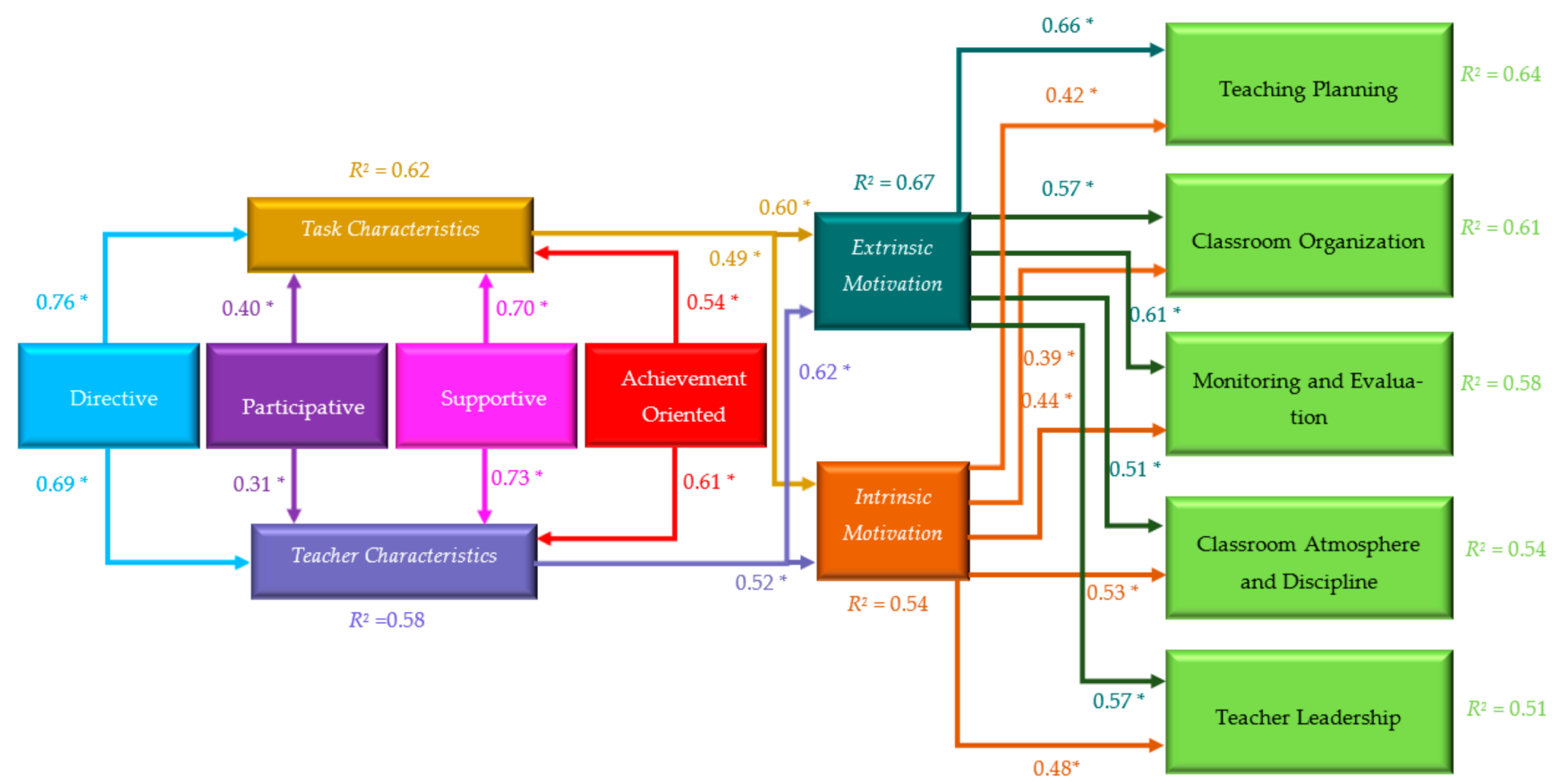

Figure 4. PGT research model with significant standardized paths; $\beta$ Values are Standardized Regression Coefficients, ${ }^{*} p<0.01$, and $\mathrm{n}=2469$; Model Fit Indexes: $\chi 2=1987.12 \mathrm{df}=895.09, \chi 2 / \mathrm{df}=2.22, p<0.01, \mathrm{RMSEA}=0.06, \mathrm{GFI}=0.89$, $\mathrm{AGFI}=0.90, \mathrm{SRMR}=0.06, \mathrm{CFI}=0.92, \mathrm{IFI}=0.94, \mathrm{NNFI}=0.93, \mathrm{NFI}=0.95, \mathrm{RFI}=0.91, \mathrm{PNFI}=0.71, \mathrm{PGFI}=0.64$.

Table 4. Indirect path/effect estimates.

\begin{tabular}{|c|c|c|c|c|c|c|c|c|c|c|c|}
\hline & Paths & Effect & & Paths & Effect & & Paths & Effect & & Paths & Effect \\
\hline 1 & $\mathrm{DL} \rightarrow \mathrm{TC} \rightarrow \mathrm{EM} \rightarrow \mathrm{TP}$ & 0.30 & 21 & $\mathrm{DL} \rightarrow \mathrm{TC} \rightarrow \mathrm{IM} \rightarrow \mathrm{TP}$ & 0.156 & 41 & $\mathrm{DL} \rightarrow \mathrm{TC} \rightarrow \mathrm{EM} \rightarrow \mathrm{TP}$ & 0.28 & 61 & $\mathrm{DL} \rightarrow \mathrm{TC} \rightarrow \mathrm{IM} \rightarrow \mathrm{TP}$ & 0.15 \\
\hline 2 & $\mathrm{PL} \rightarrow \mathrm{TC} \rightarrow \mathrm{EM} \rightarrow \mathrm{TP}$ & 0.15 & 22 & $\mathrm{PL} \rightarrow \mathrm{TC} \rightarrow \mathrm{IM} \rightarrow \mathrm{TP}$ & 0.08 & 42 & $\mathrm{PL} \rightarrow \mathrm{TC} \rightarrow \mathrm{EM} \rightarrow \mathrm{TP}$ & 0.12 & 62 & $\mathrm{PL} \rightarrow \mathrm{TC} \rightarrow \mathrm{IM} \rightarrow \mathrm{TP}$ & 0.06 \\
\hline 3 & $\mathrm{SL} \rightarrow \mathrm{TC} \rightarrow \mathrm{EM} \rightarrow \mathrm{TP}$ & 0.27 & 23 & $\mathrm{SL} \rightarrow \mathrm{TC} \rightarrow \mathrm{IM} \rightarrow \mathrm{TP}$ & 0.14 & 43 & $\mathrm{SL} \rightarrow \mathrm{TC} \rightarrow \mathrm{EM} \rightarrow \mathrm{TP}$ & 0.29 & 63 & $\mathrm{SL} \rightarrow \mathrm{TC} \rightarrow \mathrm{IM} \rightarrow \mathrm{TP}$ & 0.15 \\
\hline 4 & $\mathrm{AOL} \rightarrow \mathrm{TC} \rightarrow \mathrm{EM} \rightarrow \mathrm{TP}$ & 0.21 & 24 & $\mathrm{AOL} \rightarrow \mathrm{TC} \rightarrow \mathrm{IM} \rightarrow \mathrm{TP}$ & 0.11 & 44 & $\mathrm{AOL} \rightarrow \mathrm{TC} \rightarrow \mathrm{EM} \rightarrow \mathrm{TP}$ & 0.24 & 64 & $\mathrm{AOL} \rightarrow \mathrm{TC} \rightarrow \mathrm{IM} \rightarrow \mathrm{TP}$ & 0.13 \\
\hline 5 & $\mathrm{DL} \rightarrow \mathrm{TC} \rightarrow \mathrm{EM} \rightarrow \mathrm{CO}$ & 0.25 & 25 & $\mathrm{DL} \rightarrow \mathrm{TC} \rightarrow \mathrm{IM} \rightarrow \mathrm{CO}$ & 0.14 & 45 & $\mathrm{DL} \rightarrow \mathrm{TC} \rightarrow \mathrm{EM} \rightarrow \mathrm{CO}$ & 0.24 & 65 & $\mathrm{DL} \rightarrow \mathrm{TC} \rightarrow \mathrm{IM} \rightarrow \mathrm{CO}$ & 0.13 \\
\hline 6 & $\mathrm{PL} \rightarrow \mathrm{TC} \rightarrow \mathrm{EM} \rightarrow \mathrm{CO}$ & 0.13 & 26 & $\mathrm{PL} \rightarrow \mathrm{TC} \rightarrow \mathrm{IM} \rightarrow \mathrm{CO}$ & 0.07 & 46 & $\mathrm{PL} \rightarrow \mathrm{TC} \rightarrow \mathrm{EM} \rightarrow \mathrm{CO}$ & 0.10 & 66 & $\mathrm{PL} \rightarrow \mathrm{TC} \rightarrow \mathrm{IM} \rightarrow \mathrm{CO}$ & 0.06 \\
\hline 7 & $\mathrm{SL} \rightarrow \mathrm{TC} \rightarrow \mathrm{EM} \rightarrow \mathrm{CO}$ & 0.23 & 27 & $\mathrm{SL} \rightarrow \mathrm{TC} \rightarrow \mathrm{IM} \rightarrow \mathrm{CO}$ & 0.13 & 47 & $\mathrm{SL} \rightarrow \mathrm{TC} \rightarrow \mathrm{EM} \rightarrow \mathrm{CO}$ & 0.25 & 67 & $\mathrm{SL} \rightarrow \mathrm{TC} \rightarrow \mathrm{IM} \rightarrow \mathrm{CO}$ & 0.21 \\
\hline 8 & $\mathrm{AOL} \rightarrow \mathrm{TC} \rightarrow \mathrm{EM} \rightarrow \mathrm{CO}$ & 0.184 & 28 & $\mathrm{AOL} \rightarrow \mathrm{TC} \rightarrow \mathrm{IM} \rightarrow \mathrm{CO}$ & 0.10 & 48 & $\mathrm{AOL} \rightarrow \mathrm{TC} \rightarrow \mathrm{EM} \rightarrow \mathrm{CO}$ & 0.21 & 68 & $\mathrm{AOL} \rightarrow \mathrm{TC} \rightarrow \mathrm{IM} \rightarrow \mathrm{CO}$ & 0.12 \\
\hline 9 & $\mathrm{DL} \rightarrow \mathrm{TC} \rightarrow \mathrm{EM} \rightarrow \mathrm{ME}$ & 0.278 & 29 & $\mathrm{DL} \rightarrow \mathrm{TC} \rightarrow \mathrm{IM} \rightarrow \mathrm{ME}$ & 0.16 & 49 & $\mathrm{DL} \rightarrow \mathrm{TC} \rightarrow \mathrm{EM} \rightarrow \mathrm{ME}$ & 0.26 & 69 & $\mathrm{DL} \rightarrow \mathrm{TC} \rightarrow \mathrm{IM} \rightarrow \mathrm{ME}$ & 0.157 \\
\hline 10 & $\mathrm{PL} \rightarrow \mathrm{TC} \rightarrow \mathrm{EM} \rightarrow \mathrm{ME}$ & 0.14 & 30 & $\mathrm{PL} \rightarrow \mathrm{TC} \rightarrow \mathrm{IM} \rightarrow \mathrm{ME}$ & 0.08 & 50 & $\mathrm{PL} \rightarrow \mathrm{TC} \rightarrow \mathrm{EM} \rightarrow \mathrm{ME}$ & 0.11 & 70 & $\mathrm{PL} \rightarrow \mathrm{TC} \rightarrow \mathrm{IM} \rightarrow \mathrm{ME}$ & 0.07 \\
\hline 11 & $\mathrm{SL} \rightarrow \mathrm{TC} \rightarrow \mathrm{EM} \rightarrow \mathrm{ME}$ & 0.25 & 31 & $\mathrm{SL} \rightarrow \mathrm{TC} \rightarrow \mathrm{IM} \rightarrow \mathrm{ME}$ & 0.15 & 51 & $\mathrm{SL} \rightarrow \mathrm{TC} \rightarrow \mathrm{EM} \rightarrow \mathrm{ME}$ & 0.27 & 71 & $\mathrm{SL} \rightarrow \mathrm{TC} \rightarrow \mathrm{IM} \rightarrow \mathrm{ME}$ & 0.16 \\
\hline 12 & $\mathrm{AOL} \rightarrow \mathrm{TC} \rightarrow \mathrm{EM} \rightarrow \mathrm{ME}$ & 0.19 & 32 & $\mathrm{AOL} \rightarrow \mathrm{TC} \rightarrow \mathrm{IM} \rightarrow \mathrm{ME}$ & 0.11 & 52 & $\mathrm{AOL} \rightarrow \mathrm{TC} \rightarrow \mathrm{EM} \rightarrow \mathrm{ME}$ & 0.23 & 72 & $\mathrm{AOL} \rightarrow \mathrm{TC} \rightarrow \mathrm{IM} \rightarrow \mathrm{ME}$ & 0.13 \\
\hline 13 & $\mathrm{DL} \rightarrow \mathrm{TC} \rightarrow \mathrm{EM} \rightarrow \mathrm{CD}$ & 0.23 & 33 & $\mathrm{DL} \rightarrow \mathrm{TC} \rightarrow \mathrm{IM} \rightarrow \mathrm{CD}$ & 0.19 & 53 & $\mathrm{DL} \rightarrow \mathrm{TC} \rightarrow \mathrm{EM} \rightarrow \mathrm{CD}$ & 0.21 & 73 & $\mathrm{DL} \rightarrow \mathrm{TC} \rightarrow \mathrm{IM} \rightarrow \mathrm{CD}$ & 0.19 \\
\hline 14 & $\mathrm{PL} \rightarrow \mathrm{TC} \rightarrow \mathrm{EM} \rightarrow \mathrm{CD}$ & 0.12 & 34 & $\mathrm{PL} \rightarrow \mathrm{TC} \rightarrow \mathrm{IM} \rightarrow \mathrm{CD}$ & 0.10 & 54 & $\mathrm{PL} \rightarrow \mathrm{TC} \rightarrow \mathrm{EM} \rightarrow \mathrm{CD}$ & 0.09 & 74 & $\mathrm{PL} \rightarrow \mathrm{TC} \rightarrow \mathrm{IM} \rightarrow \mathrm{CD}$ & 0.08 \\
\hline 15 & $\mathrm{SL} \rightarrow \mathrm{TC} \rightarrow \mathrm{EM} \rightarrow \mathrm{CD}$ & 0.21 & 35 & $\mathrm{SL} \rightarrow \mathrm{TC} \rightarrow \mathrm{IM} \rightarrow \mathrm{CD}$ & 0.18 & 55 & $\mathrm{SL} \rightarrow \mathrm{TC} \rightarrow \mathrm{EM} \rightarrow \mathrm{CD}$ & 0.23 & 75 & $\mathrm{SL} \rightarrow \mathrm{TC} \rightarrow \mathrm{IM} \rightarrow \mathrm{CD}$ & 0.20 \\
\hline 16 & $\mathrm{AOL} \rightarrow \mathrm{TC} \rightarrow \mathrm{EM} \rightarrow \mathrm{CD}$ & 0.16 & 36 & $\mathrm{AOL} \rightarrow \mathrm{TC} \rightarrow \mathrm{IM} \rightarrow \mathrm{CD}$ & 0.14 & 56 & $\mathrm{AOL} \rightarrow \mathrm{TC} \rightarrow \mathrm{EM} \rightarrow \mathrm{CD}$ & 0.19 & 76 & $\mathrm{AOL} \rightarrow \mathrm{TC} \rightarrow \mathrm{IM} \rightarrow \mathrm{CD}$ & 0.16 \\
\hline 17 & $\mathrm{DL} \rightarrow \mathrm{TC} \rightarrow \mathrm{EM} \rightarrow \mathrm{TL}$ & 0.25 & 37 & $\mathrm{DL} \rightarrow \mathrm{TC} \rightarrow \mathrm{IM} \rightarrow \mathrm{TL}$ & 0.17 & 57 & $\mathrm{DL} \rightarrow \mathrm{TC} \rightarrow \mathrm{EM} \rightarrow \mathrm{TL}$ & 0.24 & 77 & $\mathrm{DL} \rightarrow \mathrm{TC} \rightarrow \mathrm{IM} \rightarrow \mathrm{TL}$ & 0.17 \\
\hline 18 & $\mathrm{PL} \rightarrow \mathrm{TC} \rightarrow \mathrm{EM} \rightarrow \mathrm{TL}$ & 0.13 & 38 & $\mathrm{PL} \rightarrow \mathrm{TC} \rightarrow \mathrm{IM} \rightarrow \mathrm{TL}$ & 0.09 & 58 & $\mathrm{PL} \rightarrow \mathrm{TC} \rightarrow \mathrm{EM} \rightarrow \mathrm{TL}$ & 0.10 & 78 & $\mathrm{PL} \rightarrow \mathrm{TC} \rightarrow \mathrm{IM} \rightarrow \mathrm{TL}$ & 0.07 \\
\hline 19 & $\mathrm{SL} \rightarrow \mathrm{TC} \rightarrow \mathrm{EM} \rightarrow \mathrm{TL}$ & 0.23 & 39 & $\mathrm{SL} \rightarrow \mathrm{TC} \rightarrow \mathrm{IM} \rightarrow \mathrm{TL}$ & 0.16 & 59 & $\mathrm{SL} \rightarrow \mathrm{TC} \rightarrow \mathrm{EM} \rightarrow \mathrm{TL}$ & 0.25 & 79 & $\mathrm{SL} \rightarrow \mathrm{TC} \rightarrow \mathrm{IM} \rightarrow \mathrm{TL}$ & 0.18 \\
\hline 20 & $\mathrm{AOL} \rightarrow \mathrm{TC} \rightarrow \mathrm{EM} \rightarrow \mathrm{TL}$ & 0.18 & 40 & $\mathrm{AOL} \rightarrow \mathrm{TC} \rightarrow \mathrm{IM} \rightarrow \mathrm{TL}$ & 0.12 & 60 & $\mathrm{AOL} \rightarrow \mathrm{TC} \rightarrow \mathrm{EM} \rightarrow \mathrm{TL}$ & 0.21 & 80 & $\mathrm{AOL} \rightarrow \mathrm{TC} \rightarrow \mathrm{IM} \rightarrow \mathrm{TL}$ & 0.15 \\
\hline
\end{tabular}

Only significant paths/effects are shown; DLS, directive leadership behavior; PLS, participative leadership behavior; SLS, supportive leadership behavior; AOLS, achievement-oriented leadership behavior; TC, task characteristics; TC, teacher characteristics; EM, extrinsic motivation; IM, intrinsic motivation; TP, teaching planning; $\mathrm{CO}$, classroom organization; $\mathrm{ME}$, monitoring and evaluation; $\mathrm{CD}$, classroom atmosphere and discipline; TL, teacher leadership.

The table further shows that, although all the paths from participative leadership to teacher job performance significantly promoted teacher job performance, the lowest total SRC weights provided evidence that participative principals were not successful in sustaining the job-oriented development of teachers in the schools. The lowest total SRC ( $\beta=0.06, p<0.01)$ weight was calculated from participative leadership through teacher characteristics and teachers' extrinsic motivation to teaching planning.

The path analysis findings substantiated the research model. The results from Figure 4 and Table 4 confirmed the effective pathway mechanism of PGT in terms of leadership behaviors, task characteristics, teacher characteristics, extrinsic motivation, and intrinsic 
motivation for teachers' job-oriented sustainable development by promoting each KPI of teachers' job performance.

Additionally, the explanatory powers over $50 \%$ corroborated this sustainable development when supportive and achievement-oriented leadership have an encouraging and favorable function in schools. The explanatory power of (A) collective principal leadership behaviors versus task characteristics and teacher characteristics were $62 \%$ and $58 \%$; (B) task characteristics and teacher characteristics versus extrinsic motivation were $67 \%$; (C) task characteristics and teacher characteristics versus intrinsic motivation were $54 \%$; and (D) teachers' extrinsic and intrinsic motivation versus teacher leadership, atmosphere, and discipline, classroom, classroom organization, teaching planning, monitoring, and evaluation were $64 \%, 61 \%, 58 \%, 54 \%$, and $51 \%$, respectively.

\section{Elucidation of Findings}

This study aimed to understand the mechanism of leadership path-goal theory for teachers' job-oriented development in private secondary schools in Pakistan.

The core purpose of PGT is to support followers in overcoming the obstacles that prevent them from working. In diverse organizational work settings, anything could appear to be a roadblock to teachers, thereby creating troubles on the job. In particular, roadblocks lead teachers toward threats and frustration due to excessive uncertainties. In such work conditions, PGT recommends that school principals and leaders provide directions and support to teachers by removing the obstructions preventing teachers' motivation and goal achievement. As a result, teachers' expectations, goal accomplishment, and task completion efficiency are increased, which finally take the job performance of teachers at the top rank [21] to promote and sustain teachers' job-oriented development in schools.

\subsection{Mechanism of Organizational Work Settings for Teachers' Job-Oriented Development}

The path-goal theory pays attention to leadership behaviors and contingency factors including the motivation of followers (teachers) and their performance [21]. The path analysis findings explored the responses of teachers on the instruments to discover significant paths for substantiating the research model from PGT independent variables (leadership behaviors) to dependent variables (teachers' job performance KPIs) mediated by contingency factors (task and teacher characteristics) and teachers' motivation (extrinsic and intrinsic motivation).

The present study's findings indicated an overall positive pathway mechanism from PGT leadership behaviors to the KPIs of teacher job performance through/mediating by the contingency factors of PGT, as well as significant relationships among principal leadership behaviors, task characteristics and teacher characteristics, task characteristics and teacher motivation, teacher characteristics, and teacher motivation, and teacher motivation and the KPIs of teacher job performance. It was evidenced that PGT effectively motivates followers and promotes their job-oriented development in directive organizational work settings. Moreover, it was also corroborated that PGT helps leaders explain to their followers what to do, how to do it, and when to do it.

Northouse [21] stated that directive leadership is useful in unstructured tasks when subordinates are new; participative leadership is beneficial when leaders need suggestions from subordinates and skillful followers who are ready to take on responsibilities. However, the present study findings, particularly the path analysis findings, demonstrated that principals did not require teachers' suggestions due to highly structured tasks. The possible reason is that there are dogmatic SOPs in the schools, with the head offices of schools circulating work procedures, working standards, supporting material, and other related protocol documents as SOPs. Hence, participative leadership behavior is not beneficial in the studied schools. Saleem, Aslam, Yin, and Rao [26] argued that participative leadership is not useful when the job duties of teachers are complicated and vague and when their 
success objectives are very challenging; school leaders are obliged to complete the tasks, and teachers must perform their tasks as per their required level of performance.

In the studied schools, mean scores greater than a threshold of 7.75 , explanatory power, and a higher correlation coefficient of task characteristics indicated that head offices set organizational goals and formulated dogmatic SOPs to accomplish these goals. In such organizational settings, the present study's findings corroborated the minimum impact of principal participatory leadership on the teacher job performance KPIs through task characteristics, teacher characteristics, and teacher motivation. The outcomes revealed that a principal's participative leadership provides partial or fails to motivate teachers to complete their jobs effectively.

Moreover, the relatively minimal SRC of participative leadership substantiated principals' directive leadership effectiveness in contingency when tasks are complicated and teachers are inexperienced. Northouse [21] supported this claim that directive leadership gives followers directions to perform their jobs effectively and successfully to attain job performance goals. As found by Miller [8], a principal had to be autocratic and employ a job-oriented leadership behavior to improve the professional attitude of teachers because "a principal is a problem solver and a school improvement agent" (p. 108).

\subsection{Functionality of PGT for Teachers' Job-Oriented Development}

The results of the SEM analytic and Pearson correlation corroborated the notion that directive leadership is effective in directive goal settings. Teachers must complete their job tasks by following the job's dogmatic SOPs to attain challenging job goals. Moreover, the present study's findings highlighted the significant positive association between principals ${ }^{\prime}$ directive leadership behavior and teachers' job performance. This finding is similar to that of the study of Mwangi (2013), which depicts the supportive and accommodative role of teaching duties.

On the other hand, a significant positive association within the participative leadership behavior of principals along with teachers' KPIs job was found in the studied schools; although the relationship was positive, it was feeble and inadequate. Omeke Faith and Onah Kenneth [55] noted the enhancement of job performance and satisfaction of teachers due to democratic (participative) leadership behaviors in the investigated schools.

The findings confirmed the satisfactory level of teacher job performance due to directive leadership in the schools. The average mean score indicated the positivity and satisfactory level of principal leadership behaviors along with teachers' job performance KPIs in the secondary schools $[14,26]$. Thus, mean score values greater than the threshold of 3.75 of the supportive and directive as well as achievement-oriented leadership behaviors evidenced a satisfactory level. However, less-than-threshold mean scores of participative leadership behavior evidenced the lowest effect, or an adverse effect, on teacher job performance.

The findings from path analysis confirmed the favorable role of the supportive behavior of leadership that focuses on accomplishment to ensure the beneficial use of directive leadership in teachers' job performance. The findings further corroborated the idea that teachers complete their tasks and finish their jobs effectively under the directive leadership of principals. The highest positive SRC weights and Pearson correlation coefficient values of directive leadership proved the claim of success in terms of the time for completion of the tasks and jobs of teachers, and more than 0.50 explanatory powers that supported this claim statistically verified the effectiveness of directive leadership in promoting teachers job-oriented development in the studied schools in Pakistan.

Duties with directional execution support from principals in challenging tasks and teacher characteristics at a lower level evidenced the dominance of directive leadership in the studied area and work settings; herein, extrinsic benefits spur the teachers' motivation. Bunmi [56] endorsed this argument in his research, i.e., that directive leadership consists of task instructions, action plans, and completion time. Thus, these are the components of directive leadership $[57,58]$. 
Additionally, the present study's findings revealed no significant gender differences, generally, on the variables except for directive leadership, task characteristics, and monitoring and evaluation. However, the overall effect size of gender differences was minimal. This confirmed that gender does not affect teachers' performance due to the identical mechanisms of PGT, dogmatic working SOPs, in-time job directions, and support for male and female teachers in the studied schools.

Leadership as an interpersonal phenomenon empowers goals' accomplishment through mutual endeavors [59] in terms of path-goal theory. In brief, directive leadership is incorporated to advance the performance of teachers by removing the interruption preventing performance sustainability. This salient standpoint is in correspondence with Smith [60], who evinced directive leadership to amplify productivity by reducing cost. Additionally, secondary schools in the private sector have different motivations than public sector schools. Financial gains are the prime goal associated with the other targets determined by the schools in the private sector [61].

Furthermore, the present study's findings uncovered significant positive and largesized associations among the supportive and achievement-oriented leadership behaviors of principals as well as teachers' job performance. This finding is consistent with the inquiry of Wachira et al. [62], which divulged a significantly positive and strong association between the leadership behaviors of principals and teachers' job performance in Kieni West Sub-County.

Additionally, the findings reflected the picture of challenging goals and a set of high-performance standards under the achievement-oriented leadership of principals in the studied schools in Pakistan. A significant positive and strong relationship between leadership focusing on accomplishment and KPIs for teacher work performance showed the challenges of achieving goals and improvement in teacher job performance. Yazdanpanah and Afrassiabi [63] supported this standpoint that achievement-oriented leadership amends and fosters the job performance of subordinates.

\subsection{Favorable Role of Supportive and Achievement-Oriented Leadership}

The most powerful positive influence on teaching practice, in particular, was that of directive leadership by means of all the paths. The present study corroborated this in two potential ways: (1) achievement-oriented school principals and leaders constantly set challenging objectives for teachers to accomplish and (2) a supporting behavior from leaders helps teachers address challenges that discourage them from achieving their targets.

The results of the path analysis substantiated this claim, particularly the favorable role of achievement-oriented and supportive leadership. Principals frequently set challenging targets for teachers to achieve and offer help to teachers in attaining these targets. Thus, the favorable role of achievement-oriented and supportive leadership turns directive leadership into effective leadership, and directive school leaders and principals offer support to teachers in finishing their jobs effectively. Northouse [21] also supported this point that directive leaders guide their followers with explicit descriptions as to what to do, when to do it, and how to do it.

Effective leadership has explicit expectations and a precise vision [39], which foster organizational performance toward organizational goal accomplishment. Along these lines, encouraging rewards, compensations, target achievement incentives, and other attached benefits motivated teachers in the studied schools. The findings uncovered the major effect of extrinsic motivation on each of the KPIs of teachers' job performance. Richardson et al. [64], Elsworth [65], Staw [66], and Sansone and Harackiewicz [67] specified that extrinsic motivation increases the performance of staff and teachers.

In target-oriented organizational settings, directive leadership shows concern with regard to attaining organizational goals, while achievement-oriented leadership sets job targets to attain organizational goals [56]. Supportive leadership provides continued assistance to followers in accomplishing job targets and organizational goals in target- 
oriented work settings. In this way, achievement-oriented and supportive leadership plays a critical role in increasing effectiveness above that of the directive leadership.

Along these lines, Northouse [21] specified that supportive leadership increases skilled employees' confidence to carry out structured tasks because followers lack confidence; however, they are skillful workers. On the other hand, achievement-oriented leadership shows confidence, provides motivation, and sets challenging, rewarded goals for experienced and novice subordinates to perform and complete structured and unstructured tasks [20]. The present study's findings confirmed the favorable role of supportive and achievement-oriented leadership in the studied schools, as claimed by House $[17,20]$ in [21].

The findings from SEM and correlation and descriptive statistics collectively validated that both of the behaviors were encouraged and backed up the directive leadership to organize the job-finishing directions when tasks are complex, the level of motivation is high, and teachers are skillful, while school principals direct and motivate teachers to achieve job goals [68], being facilitators and problem solvers [7].

To get all or some of the required benefits from a path-goal theory of leadership, principals must promote and maintain the continuous development of teachers and sustain it in the long run. They should have trust in the competencies of teachers, that they will accomplish demanding objectives. The consumer of PGT notifies their adherents to know their aspirations, and then guides them in achieving organizational goals, regularly setting attention-grabbing targets with possible high-performance exceptions, providing backup work support, trusting in subordinate capability, and facilitating their continued performance improvement [21].

Therefore, this underlying selection is correlated with the PGT directive attribute and offers new empirical substantiation with a statistical endorsement to support the statement that teachers effectively complete their objectives and achieve a better level of performance due to supporting job directions given by school principals.

\subsection{Principal Leadership Behavior and Previous Studies}

The teachers substantiated that most school principals were directive leaders, followed by achievement-oriented and supportive, in the studied secondary schools in Pakistan. Participative was the least employed leadership behavior in the schools. This means that directive leadership behavior was the preferred leadership behavior among the majority of principals in the studied schools. Rafiq Awan and Mahmood [40] had a similar finding at the university level in Pakistan. Werang and Lena [39] reported that the mainstream of high school principals was to introduce autocratic leadership behavior into routine practice in Merauke regency, Papua, Indonesia.

The study finding reaffirms Duze's (2012) outcome, in which autocratic (directive) leadership behavior was the most practiced and powerful leadership behavior in Delta State's secondary schools in Nigeria. However, this is in partial disagreement with the result of Adeyemi [69], who found a moderate level of teacher job performance in public senior secondary schools where principals preferred democratic (participative) leadership behavior in Ondo State, Nigeria.

The estimations of Pearson correlation and mean values confirmed the highest positive and significant utility of directive leadership, supportive leadership, and achievementoriented leadership behaviors, respectively, to promote each of the KPIs of teacher job performance in the studied schools. On the other hand, principals' participative leadership behavior had minor or no effects on promoting the KPIs of teacher job performance in the studied schools.

Adeyemi [69] confirmed better job performance under school principals' autocratic leadership behavior than under democratic leadership. This finding was partly in line with the work of Duze [41]. Ozuruoke et al. [70] found inadequate job performance in schools where principals showed democratic leadership behavior in the researched schools. Kozaala [42] found that school principals used directional and instructional language while negotiating with teachers. 
Generally, participative leadership is useful in the academic world, specifically in public school matters. For instance, Imhangbe, Okecha, and Obozuwa [10] said that democratic leadership was practiced at a large scale by principals in public sector secondary schools in the Edo Central Senatorial District of Nigeria. It was the most effective leadership in the research area; they came to know more about the negative effect of autocratic leadership behavior on teacher job performance. However, these outcomes are in contrast to those of the present study due to the dissimilar contexts and diverse cultures, environments, and, especially, organizational settings.

Hence, PGT leadership behaviors are significant and can sustain teachers' job-oriented development in the long run in private secondary schools through a set of guidelines and instructions for carrying out tasks and achieving difficult goals when principals and school leaders are facilitators and problem solvers and help teachers finish promising job tasks.

\section{Conclusions and Recommendations}

This research yielded several encouraging findings, including that directive leadership positively affects teacher job performance KPIs due to the helpful and favorable role of the achievement-oriented and supportive leadership behaviors of principals in the studied schools.

Directive leaders clarify paths and remove obstacles when tasks are ambiguous, unclear, and complex. Therefore, teachers must follow dogmatic SOPs in authoritarian organizational work settings to accomplish their challenging tasks and organizational goals. The rewarding and challenging goals motivate teachers to pursue superior job performance, and on-the-job support lets teachers accomplish their job targets. In particular, on-the-job backup support sustains the job-oriented development of teachers. The empirical findings substantiated the beneficial use of directive leadership in all situations. The findings encouraged principals to use a directive leadership behavior to complete jobs by and through teachers.

The highest explanatory power of teachers' extrinsic motivation backs up the helpful role of achievement-oriented leadership and supportive leadership in articulating the effectiveness of directive leadership when tasks are highly structured, situations are ambiguous and unclear, and followers must follow dogmatic SOPs to finish their jobs.

While PGT behaviors were observed effectively in the studied context, the participative behavior of leadership was observed to be either problematic or unhelpful for all teacher job performance constructs. Thus, training school leaders in the valuable practice of the participative behavior of leadership functions can be productive.

Although considering the consequences and connections between principals' leadership behaviors and the job performance of teachers is significant, participatory leadership must be constructively adopted; in particular, teachers' autonomy and independence must be encouraged to greatly boost their work performance in secondary schools, because, as observed by Oplatka [71] and Hallinger and Kantamara [72], the participative behavior of leadership encourages a family environment in schools that fulfills teachers' requirements of shared accountability and the motivation of teachers over the long term.

School leaders should transform the effects of participative leadership into constructive consequences, practice it intelligently, and engage in a sensible amalgamation with contrary leadership behaviors to sustain teachers' job performance in the long run. Linear and systematic thinking might specify the constructive transformation of participative leadership in schools. Therefore, training programs for principals, with a focus on the participatory functions of leadership for useful practice, can be productive.

\section{Limitation and Future Studies}

The present research was limited primarily to private secondary schools in a nonWestern, Asian-context, developing country. Thus, a diverse conceptualization of contextual and cultural influences is essential for validating the possible explanations for the unexpected participative behavior of this report's leadership results. Moreover, a com- 
parative investigation among private and public schools could yield meaningful results. Of note, this research was limited to the distinctive perspective of teachers. Hence, in future studies, the perspective of school leaders taken on board will yield interesting results. Subsequently, the self-reported questionnaire was used. Next, the current research was limited to the four path-goal theory leadership behaviors, four contingency factors, and five teacher job performance constructs. Additional factors, such as other leadership behaviors and teacher job performance KPIs, particularly the organizational goal-setting mechanism, informational justice, followers' goal reactions, and goal commitment, could yield insightful future results at a higher education level.

Author Contributions: A.S.: Writing—original draft, Writing—review and editing, Conceptualization, Formal analysis, Methodology, Visualization, and Investigation; L.W.: Methodology, Resources, Validation, Visualization, and Writing—review and editing; S.A.: Conceptualization, Writing-review and editing, Data curation, Investigation, Methodology, and Visualization; T.Z.: Project administration, Resources, Supervision, Software, and Validation. All authors have read and agreed to the published version of the manuscript.

Funding: This research received no external funding.

Institutional Review Board Statement: Not applicable.

Informed Consent Statement: Informed consent was obtained from all subjects involved in the study.

Data Availability Statement: Not applicable.

Conflicts of Interest: The authors declare no conflict of interest.

\section{Appendix A}

Table A1. Goodness-of-Model-Fit (GFIs) Indices.

\begin{tabular}{ll}
\hline \multicolumn{1}{c}{ Index Name } & \multicolumn{1}{c}{ Threshold Value } \\
\hline$\chi^{2} / \mathrm{df}\left(\mathrm{Chi}^{2} /\right.$ degree of freedom) & $<3$ (Hair et al., 2010). \\
RMSEA (Root Mean Square Error of Approximation) & $<0.08$ (Hu \& Bentler, 1999). \\
GFI (Goodness of Fit Index) & $>0.85$ (Kline, 2015). \\
AGFI (Adjusted Goodness of Fit Index) & $>0.80$ (MacCallum \& Hong, 1997). \\
SRMR (Standardized Root Mean Square Residual) & $<0.08$ (Hu \& Bentler, 1999). \\
CFI (Comparative Fit Index) & $>0.90$ (Byrne, 2016). \\
IFI (Incremental Fit Index) & $>0.90$ (Byrne, 2016). \\
NNFI (Non-normed Fit Index) & $>0.90$ (Byrne, 2016). \\
NFI (Normed Fit Index) & $>0.90$ (Byrne, 2016). \\
RFI (Relative Fit Index) & $>0.90$ (Byrne, 2016). \\
PNFI (Parsimonious Normed Fit Index) & $>0.50$ (Mulaik et al., 1989). \\
PGFI (Parsimony Goodness-of-Fit Index) & $>0.50$ (Mulaik et al., 1989). \\
\hline
\end{tabular}

\section{References}

1. Shulla, K.; Filho, W.L.; Lardjane, S.; Sommer, J.H.; Borgemeister, C. Sustainable development education in the context of the 2030 Agenda for sustainable development. Int. J. Sustain. Dev. World Ecol. 2020, 27, 458-468. [CrossRef]

2. United Nations Educational, Scientific and Cultural Organization. UNESCO Moving Forward the 2030 Agenda for Sustainable Development; United Nations Educational, Scientific and Cultural Organization: Paris, France, 2017.

3. Nasibulina, A. Education for Sustainable Development and Environmental Ethics. Procedia Soc. Behav. Sci. 2015, 214, 1077-1082. [CrossRef]

4. Beveridge, D.; McKenzie, M.; Aikens, K.; Strobbe, K. A national census of sustainability in K-12 education policy: Implications for international monitoring, evaluation, and research. Can. J. Educ. Adm. Policy 2019, 188, 36-52.

5. Aslam, S. A Study on the Implementation and the Effectiveness of Distance Teacher Education Program in Pakistan: Stakeholders' Perceptions; Northeast Normal University: Changchun, China, 2019.

6. Hamilton, E. Assessing the Relationship of Principals' Leadership Styles on Teacher Satisfaction and Teacher Turnover; Northcentral University: San Diego, CA, USA, 2016.

7. Williams-Boyd, P. Educational Leadership: A Reference Handbook; Abc-clio: Santa Barbara, CA, USA, 2002.

8. Miller, P. Cultures of Educational Leadership: Global and Intercultural Perspectives; Springer: Berlin, Germany, 2016. 
9. Nsubuga, Y.K.K. Analysis of Leadership Styles and School Performance of Secondary Schools in Uganda; Nelson Mandela Metropolitan University: Port Elizabeth, South Africa, 2008.

10. Imhangbe, O.; Okecha, R.; Obozuwa, J. Principals' Leadership Styles and Teachers' Job Performance: Evidence from Edo State, Nigeria. Educ. Manag. Adm. Leadersh. 2019, 47, 909-924. Available online: https://doi.org/10.1177/1741143218764178 (accessed on 22 May 2021). [CrossRef]

11. Ministry of Federal Education and Professional Training Government of Pakistan. National Education Policy 2017-2015; Government of Pakistan: Islamabad, Pakistan, 2017.

12. World Bank. Pakistan Poverty Assessment_Poverty in Pakistan: Vulnerabilities, Social Gaps, and Rural Dynamics; World Bank: Washington, DC, USA, 2002.

13. International Finance Corporation. IFC Strategic Directions; IFC: Washington, DC, USA, 2002.

14. Saleem, A. Principal Leadership Styles and Teacher Job Performance: Perspective of Path-Goal Theory; Northeast Normal University: Changchun, China, 2020.

15. Adejumobi, F.T.; Ojikutu, R.K. School Organizational Climate and Teacher Job Performance in Lagos State, Nigeria. Discourse J. Educ. Res. 2013, 1, 26-36.

16. Evans, M.G. The effects of supervisory behavior on the path-goal relationship. Organ. Behav. Hum. Perform. 1970, 5, 277-298. [CrossRef]

17. House, R.J. A Path Goal Theory of Leader Effectiveness. Adm. Sci. Q. 1971, 16, 321. [CrossRef]

18. House, R.; Dessler, G. The Path-Goal Theory of Leadership: Some Post Hoc and A Priori Tests; Southern Illinois University Press: Carbondale, IL, USA, 1974; pp. 29-55.

19. House, R.J.; Mitchell, R. Path-goal theory of leadership. J. Contemp. Bus. 1974, 3, 81-97.

20. House, R.J. Path-goal theory of leadership: Lessons, legacy, and a reformulated theory. Leadersh. Q. 1996, 7, 323-352. [CrossRef]

21. Northouse, P.G. Leadership: Theory and Practice; Sage Publications: Thousand Oaks, CA, USA, 2018.

22. House, R.J.; Mitchell, T.R. Path-Goal Theory of Leadership; Washington University Seattle Department of Psychology: Seattle, WA, USA, 1975.

23. Fischer, C.; Malycha, C.P.; Schafmann, E. The Influence of Intrinsic Motivation and Synergistic Extrinsic Motivators on Creativity and Innovation. Front. Psychol. 2019, 10, 137. [CrossRef]

24. Reiss, S. Intrinsic and extrinsic motivation. Teach. Psychol. 2012, 39, 152-156. [CrossRef]

25. Isaac, R.G.; Zerbe, W.J.; Pitt, D.C. Leadership and motivation: The effective application of expectancy theory. J. Manag. Issues 2001, 13, 212-226.

26. Saleem, A.; Aslam, S.; Yin, H.-B.; Rao, C. Principal Leadership Styles and Teacher Job Performance: Viewpoint of Middle Management. Sustainability 2020, 12, 3390. [CrossRef]

27. Bolman, L.G.; Deal, T.E. Reframing the Path to School Leadership: A Guide for Teachers and Principals; Corwin Press: Thousand Oaks, CA, USA, 2018.

28. Hoerr, T.R. The Art of School Leadership; ASCD: Alexandria, VA, USA, 2005.

29. Parmenter, D. Key Performance Indicators: Developing, Implementing, and Using Winning KPIs; John Wiley \& Sons: Hoboken, NJ, USA, 2015.

30. Atsebeha, A.T. Principals' Leadership Styles and Their Effects on Teachers' Performance in the Tigray Region of Ethiopia; University of South Africa: Pretoria, South Africa, 2016.

31. Savage, J. Lesson Planning: Key Concepts and Skills for Teachers; Routledge: Abingdon, UK, 2014.

32. Stronge, J.H. Qualities of Effective Teachers; ASCD: Alexandria, VA, USA, 2018.

33. Unger, M.S. Organized Teacher, Happy Classroom: A Lesson Plan for Managing Your Time, Space and Materials; F+W Media, Inc.: Cincinnati, OH, USA, 2011.

34. Aslam, S.; Saleem, A.; Hali, A.U.; Zhang, B. Promoting Sustainable Development in School Classrooms: Using Reciprocal Teaching in Mathematics Education. TEM J. 2021, 10, 392-400. [CrossRef]

35. Brookhart, S.M. Formative Assessment Strategies for Every Classroom: An ASCD Action Tool; ASCD: Alexandria, VA, USA, 2010.

36. Glas, C.; Scheerens, J.; Thomas, S.M. Educational Evaluation, Assessment and Monitoring: A Systematic Approach; Taylor \& Francis: New York, NY, USA, 2006.

37. Aslam, S.; Saleem, A.; Hali, A.U.; Akram, H. Science students' perceptions of the learning environment in Science degree programs. Indian J. Sci. Technol. 2020, 13, 4003-4012. [CrossRef]

38. Bandstra, A. Beyond Control: Heart-Centered Classroom Climate and Discipline; BookBaby: Washington, DC, USA, 2016.

39. Werang, B.R.; Lena, L. Relationship between Principal's Leadership, School Organizational Climate, and Teachers' Job Performance at State Senior High Schools in Merauke Regency-Papua-Indonesia. Int. J. Educ. Res. 2014, 2, 635-640.

40. Awan, M.R.; Mahmood, K. Relationship among leadership style, organizational culture and employee commitment in university libraries. Libr. Manag. 2010, 31, 253-266. [CrossRef]

41. Duze, C.O. Leadership styles of principals and job performance of staff in secondary schools in Delta State of Nigeria. AFRREV IJAH Int. J. Arts Humanit. 2012, 1, 224-245.

42. Kozaala, E. Leadership Styles and Job Performance of Teachers in Selected Private Secondary Schools of Kamuli District, Uganda; Makerere University: Kampala, Uganda, 2012.

43. Aziri, B. Job satisfaction: A literature review. Manag. Res. Pract. 2011, 3, 77-86. 
44. Vangel, K. Employee Responses to Job Dissatisfaction. 2011, pp. 1-17. Available online: https://digitalcommons.uri.edu/cgi/ viewcontent.cgi?article=1030\&context=lrc_paper_series (accessed on 22 May 2021).

45. Khine, M.S. Application of Structural Equation Modeling in Educational Research and Practice; Springer: Berlin, Germany, 2013; Volume 7.

46. Indvik, J. A Path-Goal Theory Investigation of Superior-Subordinate Relationships; University of Wisconsin-Madison: Madison, WI, USA, 1985.

47. Hair, J.; Black, W.; Babin, B.; Anderson, R. Multivariate Data Analysis, 7th ed.; Prentice Hall: Upper Saddle River, NJ, USA, 2010.

48. Hancock, G.R.; Mueller, R.O. Structural Equation Modeling: A Second Course; Iap: Charlotte, NC, USA, 2013.

49. Byrne, B.M. Structural Equation Modeling with AMOS: Basic Concepts, Applications, and Programming; Routledge: New York, NY, USA, 2016.

50. Green, S.B.; Salkind, N.J. Using SPSS for Windows and Macintosh, Books a la Carte; Pearson: London, UK, 2016.

51. Yang, Z.; Asbury, K.; Griffiths, M.D. An Exploration of Problematic Smartphone Use among Chinese University Students: Associations with Academic Anxiety, Academic Procrastination, Self-Regulation and Subjective Wellbeing. Int. J. Ment. Health Addict. 2018, 17, 596-614. [CrossRef]

52. Cohen, J. A power primer. Psychol. Bull. 1992, 112, 155. [CrossRef] [PubMed]

53. Cohen, J. Statistical Power Analysis for the Behavioral Sciences; Routledge: New York, NY, USA, 2013.

54. Suhr, D. Step your way through Path Analysis. In Proceedings of the Western Users of SAS Software Conference Proceedings, 5 November 2008; pp. 1-10. Available online: https://www.lexjansen.com/wuss/2008/pos/pos04.pdf (accessed on 22 May 2021).

55. Omeke Faith, C.; Onah Kenneth, A. The influence of principals' leadership styles on secondary school teachers' job satis-faction. J. Educ. Soc. Res. 2012, 2, 46.

56. Bunmi, J.M. Leadership; Harper and Row Publishers: New York, NY, USA, 2007.

57. Yukl, G.A. Leadership in Organizations, 8th ed.; Pearson: Edinburgh Gate, Harlow, UK, 2013.

58. Lunenburg, F.; Ornstein, A. Educational Administration: Concepts and Practices, 3rd ed.; Wadsworth: Belmont, CA, USA, 2000.

59. Graeff, C.L. The situational leadership theory: A critical view. Acad. Manag. Rev. 1983, 8, 285-291. [CrossRef]

60. Smith, A.J. Implementing Core Values in the High-Tech Industry; Walden University: Minneapolis, MN, USA, 2011.

61. Yu, V. Principal Leadership for Private Schools Improvement: The Singapore Perspective. J. Int. Soc. Res. 2009, 1, 714-749.

62. Wachira, F.M.; Gitumu, M.; Mbugua, Z. Effect of Principals' Leadership Styles on Teachers' Job Performance in Public Secondary Schools in Kieni West Sub-County. IJHSSI 2017, 6, 72-86.

63. Yazdanpanah, Z.; Afrassiabi, R. The relationship between participative and achievement-oriented management styles and time management. Int. J. Manag. Humanit. Sci. 2014, 3, 3143-3147.

64. Richardson, P.W.; Karabenick, S.A.; Watt, H.M.G. Teacher Motivation: Theory and Practice; Taylor \& Francis: New York, NY, USA, 2014.

65. Elsworth, D.H. Motivation in Education; Nova Science Publishers: New York, NY, USA, 2009.

66. Staw, B.M. Intrinsic and Extrinsic Motivation; General Learning Press: Charlottesville, VA, USA, 1976.

67. Sansone, C.; Harackiewicz, J.M. Intrinsic and Extrinsic Motivation: The Search for Optimal Motivation and Performance; Elsevier: San Diego, CA, USA, 2000.

68. Venter, I. Worldproof Leadership: Twenty-One Leadership Perspectives for the Interconnected World; CCBS Press: Amsterdam, The Netherland, 2018.

69. Adeyemi, T. Principals leadership styles and teachers job performance in senior secondary schools in Ondo State, Nigeria. Int. J. Educ. Adm. Policy Stud. 2010, 2, 83-91.

70. Ozuruoke, A.; Ordu, P.; Abdulkarim, M. Leadership Style and Business Educators' Job Performance in Senior Secondary Schools in a Changing Environment. J. Educ. Soc. Res. 2011, 1, 149.

71. Oplatka, I. The principalship in developing countries: Context, characteristics and reality. Comp. Educ. 2004, 40, 427-448. [CrossRef]

72. Hallinger, P.; Kantamara, P. Educational Change in Thailand: Opening a window onto leadership as a cultural process. Sch Leadersh. Manag. 2000, 20, 189-205. [CrossRef] 